\title{
Influence of Echocardiographic Guidance on Positioning of the Buttoned Occluder for Transcatheter Closure of Atrial Septal Defects
}

\author{
THOMAS R. LLOYD, M.D., ROGER P. VERMILION, M.D., ROLANDO ZAMORA, M.D., \\ ACHI LUDOMIRSKY, M.D., and ROBERT H. BEEKMAN III, M.D. \\ Division of Pediatric Cardiology, Department of Pediatrics, C.S. Mott Children's Hospital, \\ The University of Michigan, Ann Arbor, Michigan; and the Steele Memorial Children's \\ Research Center, University Heart Center, and Department of Pediatrics (Cardiology), \\ The University of Arizona, Tucson, Arizona
}

Ideal position of the buttoned device for occlusion of atrial septal defects was achieved more often with transesophageal than with transthoracic echocardiographic guidance $(10 / 11$ vs $7 / 23 ; P=$ 0.001). Patients with ideal device position were less likely to have residual shunts, device unbuttoning, or atrioventricular valve regurgitation $(2 / 17 \mathrm{vs} 11 / 17 ; P=0.002)$. We therefore recommend the use of transesophageal echocardiography to guide implantation of the buttoned device. (ECHOCARDIOGRAPHY, Volume 13, March 1996)

transesophageal echocardiography, interventional cardiac catheterization

Transcatheter occlusion of atrial septal defects with the buttoned device has been reported by investigators from several centers. ${ }^{1-5}$ Although transesophageal echocardiographic (TEE) guidance has proved to be very important in implanting the Clamshell occlusion device, ${ }^{6}$ the role of echocardiographic guidance in implanting the buttoned device has not been studied. We therefore reviewed our experience with the buttoned device to determine whether TEE guidance favorably influenced device positioning or clinical complications as compared to transthoracic echocardiographic (TTE) guidance.

\section{Methods}

Records of all patients who underwent attempted transcatheter closure of secundum atrial septal defects with the buttoned device (Custom Medical Devices, Amarillo, TX, USA)

This study was supported in part by Grant MO1-RR00042 from the National Institutes of Health.

Address for correspondence and reprints: Thomas $R$. Lloyd, M.D., Pediatric Cardiology, F1310 MCHC, 1501 E. Medical Center Dr., Ann Arbor, MI 48109-0204. Fax: 313936-6267. from March 1991 through August 1992 at The University of Arizona (University Medical Center) and The University of Michigan (C.S. Mott Children's Hospital) were reviewed. Immediate results and intermediate follow-up of these patients have been reported. ${ }^{1}$ The mode of echocardiographic guidance (TTE vs TEE) for each procedure was determined, and postprocedure TTEs and/or surgical reports were reviewed to determine the position of all six arms of the device, as well as the presence and magnitude of any residual left-to-right shunt. Echocardiographic guidance was used as an adjunct to fluoroscopy in all occlusion procedures, with the mode of guidance determined by operator preference. The influence of the mode of echocardiographic guidance during the implantation procedure on device position and on residual shunting and other clinically relevant complications was analyzed by Fisher's Exact Test, with $\mathrm{P}<0.05$ indicating statistical significance.

\section{Results}

A total of 41 patients were potentially eligible for inclusion in this study. Seven patients 
LLOYD, ET AL.

TABLE I

Mode of Echocardiographic Guidance, Device Position, ${ }^{*}$ and Residual Small to Moderate Shunts After Buttoned Device Occlusion of Atrial Septal Defect

\begin{tabular}{|c|c|c|c|c|c|}
\hline Patient Number & Weight (kg) & Echo Mode & Residual Shunt & $\begin{array}{l}\text { Occluder Arm } \\
\text { Position }\end{array}$ & $\begin{array}{c}\text { Counteroccluder Arm } \\
\text { Position }\end{array}$ \\
\hline 1 & 10.8 & TTE & + & 2LA, 2RA & 2RA \\
\hline 2 & 17.0 & TTE & 0 & $4 \mathrm{LA}$ & $2 \mathrm{RA}$ \\
\hline 3 & 16.5 & TTE & 0 & 3LA, 1RA & $2 \mathrm{RA}, 1$ to TV, UB \\
\hline 4 & 24.6 & TTE & 0 & 2LA, 2RA & $2 \mathrm{RA}, 1$ to $\mathrm{TV}$ \\
\hline 5 & 18.0 & TTE & 0 & 3LA, 1RA & 2RA, UB \\
\hline 6 & 18.5 & TTE & 0 & 3LA, IRA & $2 \mathrm{RA}$ \\
\hline 7 & 15.0 & TTE & 0 & $4 \mathrm{LA}$ & $2 \mathrm{RA}, 1$ to IVC \\
\hline 8 & 42.0 & TEE & 0 & 4LA & 2RA, UB \\
\hline 9 & 15.2 & TEE & 0 & $4 \mathrm{LA}$ & $2 \mathrm{RA}$ \\
\hline 10 & 16.1 & TTE & 0 & $4 \mathrm{LA}$ & 2RA \\
\hline 11 & 12.5 & TTE & 0 & 3LA, 1RA & 2RA \\
\hline 12 & 23.3 & TTE & + & 3LA, 1RA & 2RA \\
\hline 13 & 15.9 & TTE & 0 & $4 \mathrm{LA}$ & 2RA \\
\hline 14 & 15.9 & TTE & 0 & 4LA & 2RA \\
\hline 15 & 72.6 & TEE & 0 & $4 \mathrm{LA}$ & 2RA \\
\hline 16 & 14.0 & TTE & 0 & $4 \mathrm{LA}, 1$ to $\mathrm{MV}$ & 2RA \\
\hline 17 & 75.0 & TEE & 0 & $4 \mathrm{LA}$ & 2RA \\
\hline 18 & 20.0 & TTE & 0 & 3LA, 1RA & 2RA \\
\hline 19 & 12.2 & TTE & 0 & 3LA, IRA & 2RA \\
\hline 20 & 13.0 & $\mathrm{TTE}$ & + & $3 \mathrm{LA}, 1 \mathrm{RA}$ & $2 \mathrm{RA}$ \\
\hline 21 & 16.4 & TTE & 0 & 3LA, 1RA & 2RA, UB \\
\hline 22 & 63.5 & TEE & 0 & $4 \mathrm{LA}$ & $2 \mathrm{RA}$ \\
\hline 23 & 91.0 & TEE & 0 & 4LA & 2RA \\
\hline 24 & 14.9 & TTE & 0 & $4 \mathrm{LA}$ & 2RA \\
\hline 25 & 20.4 & TEE & 0 & 4LA, 1 to $\mathrm{MV}$ & 2RA \\
\hline 26 & 66.2 & TEE & + & $4 \mathrm{LA}$ & $2 \mathrm{RA}$ \\
\hline 27 & 17.8 & TTE & 0 & 3LA, 1RA & $2 \mathrm{RA}$ \\
\hline 28 & 16.3 & TTE & 0 & $4 \mathrm{LA}$ & 2RA \\
\hline 29 & 10.3 & TTE & + & $3 \mathrm{LA}, 1 \mathrm{RA}$ & $2 \mathrm{RA}$ \\
\hline 30 & 85.4 & TEE & 0 & $4 \mathrm{LA}$ & $2 \mathrm{RA}$ \\
\hline 31 & 17.6 & TTE & 0 & 4LA, 1 to $\mathrm{MV}$ & 2RA \\
\hline 32 & 58.4 & TEE & 0 & $4 \mathrm{LA}$ & $2 \mathrm{RA}$ \\
\hline 33 & 15.4 & TTE & 0 & $4 \mathrm{LA}$ & 2RA \\
\hline 34 & 32.7 & TEE & 0 & 4LA & 2RA \\
\hline
\end{tabular}

* Ideal device position is 4LA occluder arm position, 2RA counteroccluder arm position, with no further specification. IVC: inferior vena cava; LA: left atrium; MV: mitral valve; RA: right atrium; TEE: transesophageal echocardiography; TTE: transthoracic echocardiography; TV: tricuspid valve; UB: unbuttoned.

were excluded: the procedure was abandoned without implanting a device in six patients; and TTE was inadequate to definitively indicate the position of all six device arms in one adolescent patient with Marfan's syndrome and pectus excavatum. Results from the remaining 34 patients are shown in Table I. TTE was used in 23 patients and TEE in 11 patients. Ideal device position was defined as all four occluder arms on the left atrial side of the septum, both counteroccluder arms on the right atrial side of the septum, and no impingement by the device on any structures beyond the atrial septum (Fig. 1). Ideal position was observed in 17 cases (50\%). In 13 cases, one or two occluder arms passed through the defect into the right atrium (Fig. 2). In three cases, an occluder arm extended to the mitral valve, and a counteroccluder arm extended to the tricuspid valve in two cases (both cases 

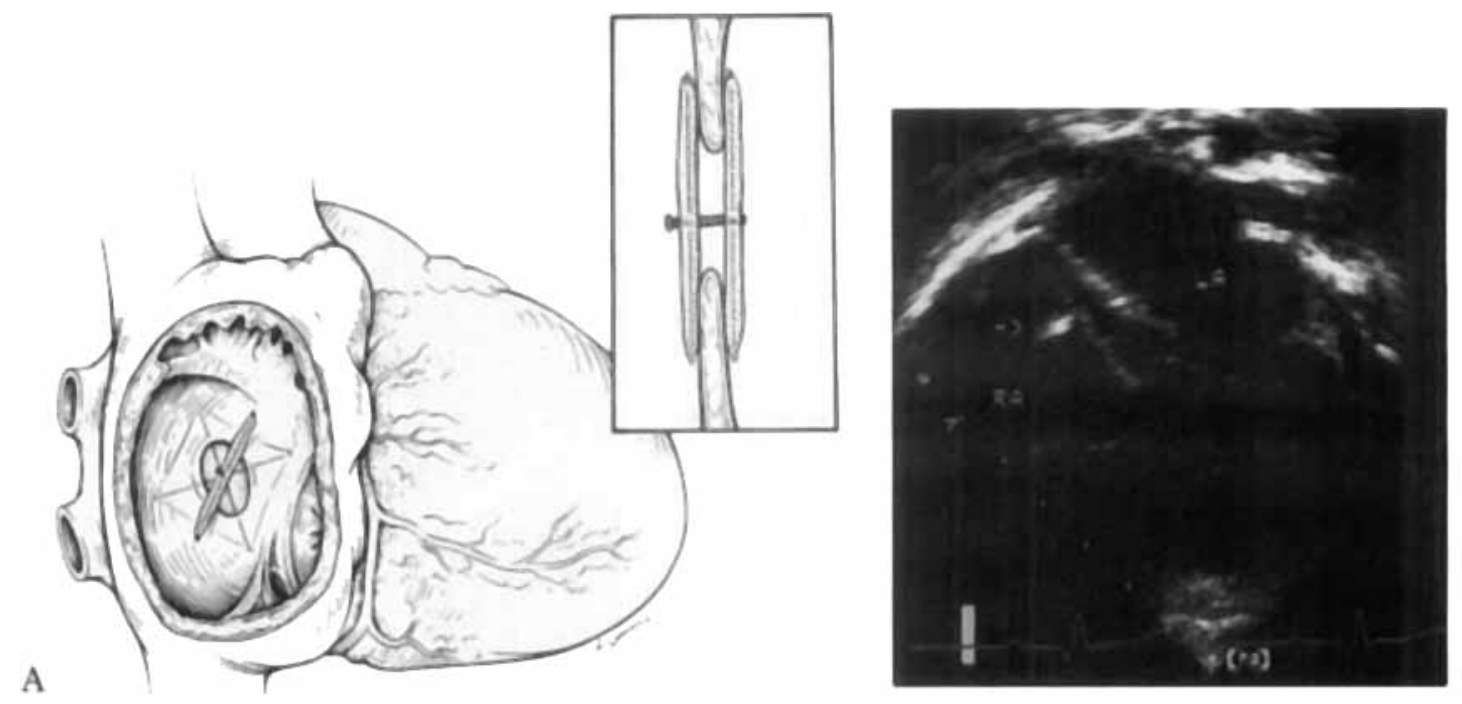

Figure 1. (A) Diagram of the buttoned device in ideal position, viewed from the right atrium (RA). The occluder can be seen in outline on the left atrial side of the septum. The insert shows the device in cross section, with the occluder and counteroccluder connected by the button loop. (B) Inverted subcostal transthoracic echocardiographic image of a buttoned device in ideal position. Occluder and counteroccluder are aligned in parallel on either side of the atrial septum. The arrow indicates the button, which has been passed through the counteroccluder to secure it to the occluder. This image is similar to the insert in panel A. LA =left atrium.

have occluder arms in the right atrium). In the remaining patient, a counteroccluder arm extended into the inferior vena cava. Of the 11 devices implanted under TEE guidance, ten were in ideal position. Only 7 of 23 devices implanted under TTE guidance were in ideal position ( $P=0.001)$.

Small-to-moderate residual left-to-right shunts (shunt fraction 0.20-0.33) were present in five patients immediately after occlusion, including four patients with occluder arms positioned in the right atrium and one patient whose device met the criteria for ideal placement. Unbuttoning of four devices occurred, three with occluder arms in the right atrium and one thought to be in ideal position. Combining the clinically significant and potentially significant complicating factors of unbuttoning, small-to-moderate residual shunts, and arm placement on atrioventricular valve apparatus, these factors were present in 3 of 11 patients in whom TEE guidance was used, compared to 10 of 23 TTE patients $(P=0.30)$. When analyzed by device position, only 2 of 17 patients with ideal device position have these factors, compared to 11 of 17 patients with nonideal device position $(P=0.002)$.

\section{Discussion}

The buttoned device was designed to be implanted without need for echocardiographic guidance. ${ }^{7}$ In our initial experience, we found both TTE and TEE guidance helpful in balloon sizing of the defects and in confirming device position and efficacy. ${ }^{8}$ The present retrospective comparison suggests that TEE guidance is associated with more accurate device placement than TTE guidance (91\% vs $30 \%$ in ideal position), similar to results reported with implantation of the Clamshell occluding device with TEE guidance ( $72 \%$ in ideal position ${ }^{9}$ ). Because patient allocation to TTE and TEE was not random, we cannot statistically exclude the possibility that the differences observed are due to selection bias. TEE guidance was used in larger patients than TTE $(56.6 \pm 25.6 \mathrm{~kg}$ vs $16.2 \pm 3.5 \mathrm{~kg}$ body weight; $\mathrm{P}<0.0001$ ), although defect diameter by balloon occlusion was no different $(14.5 \pm 5.0 \mathrm{~mm}$ vs $14.1 \pm 3.1$ 

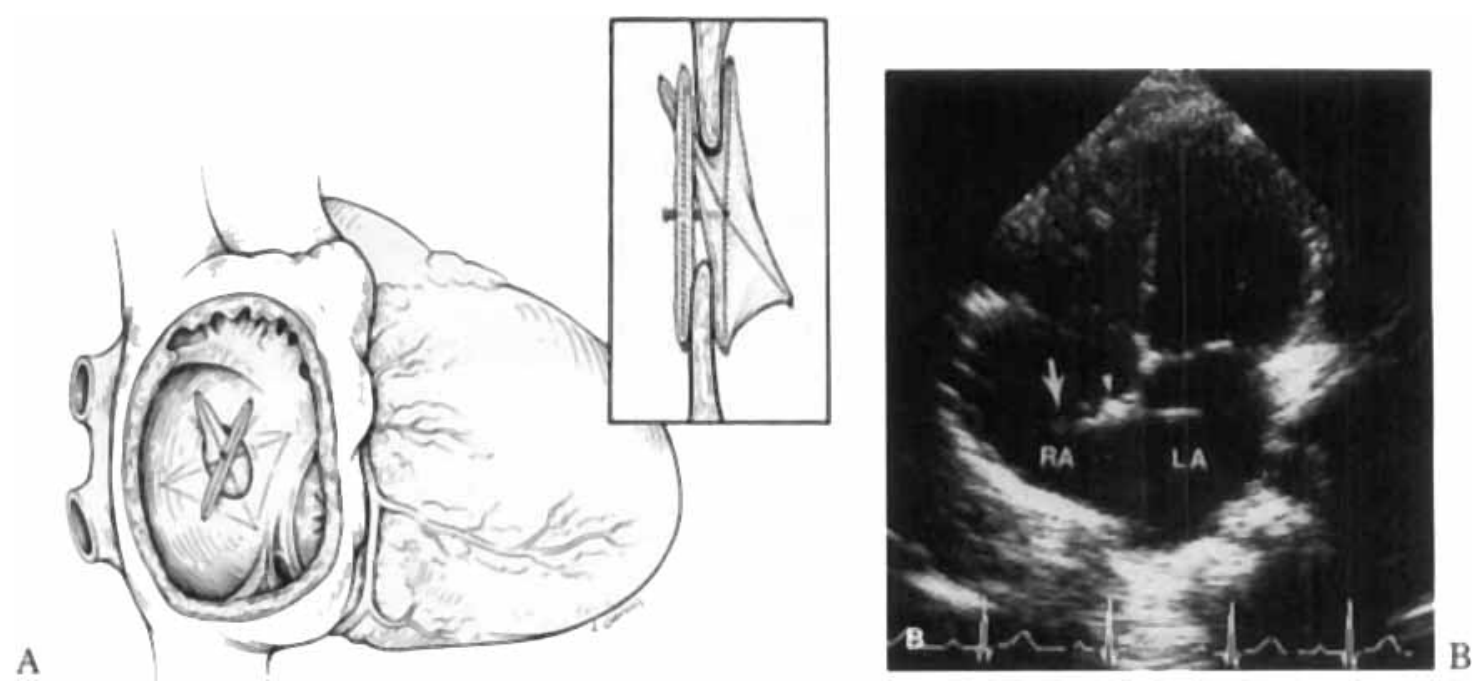

Figure 2. (A) Diagram of the buttoned device with one occluder arm passed through the atrial septal defect. The remainder of the occluder can be seen in outline on the left atrial side of the septum. The insert shows the device in cross section, with an occluder arm projecting into the right atrial cavity causing its opposite arm to project into the left atrial cavity. (B) Noninverted apical transthoracic echocardiographic image of a patient with one occluder arm of the buttoned device passed through the atrial septal defect into the right atrium (RA; arrow), causing the opposite arm to project into the left atrial cavity. The counteroccluder is imaged in cross section (arrowhead), and the button can be seen in the right atrium between the counteroccluder and the arrow. This image is similar to the inset in panel $A$, except that the counteroccluder is imaged in cross section rather than longitudinally. This buttoned device completely occluded the atrial septal defect, despite the nonideal occluder arm position. $L A=$ left atrium.

$\mathrm{mm})$. Nevertheless, we have been impressed that TEE provides more precise, real-time feedback regarding device position than does TTE, which facilitates adjustment of the delivery system until device position is optimal. TEE guidance can be used during fluoroscopy without irradiating the echocardiographer, and does not suffer the degradation of echocardiographic windows commonly experienced when patients are positioned for cardiac catheterization. Because of the time period during which this study was performed, TEE was not available for our smaller patients. With the development of smaller probes, we have used TEE guidance exclusively since 1993 , with similar results in small patients.

Ideal device position was associated with fewer potentially significant residual shunts, probably due to better occluder position against the atrial septum, and with fewer instances of unbuttoning, possibly due to less tension on the buttoning apparatus when the occluder does not protrude through the defect. By definition, no patient with ideal device position had impingement of the device on the atrioventricular valve apparatus. Achievement of ideal device position was associated with fewer clinical complications, regardless of the mode of echocardiographic guidance used, but the use of TEE guidance was strongly associated with achievement of ideal device position. Ideal device position therefore appears to be a clinically worthwhile goal. We recommend use of TEE guidance during implantation of the buttoned device in order to enhance the likelihood of achieving ideal device position.

\section{References}

1. Lloyd TR, Rao PS, Beekman RH, et al: Atrial septal defect occlusion with the buttoned device (a multi-institutional U.S. trial). Am J Cardiol 1994;73:286-291.

2. Sideris EB, Sideris SE, Thanopoulos BD, et al: 
Transvenous atrial septal defect occlusion by the buttoned device. Am J Cardiol 1990;66: 1524-1526.

3. Rao PS, Wilson AD, Levy JM, et al: Role of "buttoned" double-disc device in the management of atrial septal defects. Am Heart $J$ 1992;123:191200.

4. Sideris EB, Rao PS, Lekakis J, et al: Transvenous correction of symptomatic or oversized atrial septal defects in adults by the Sideris buttoned device. (Abstract) Circulation 1991; 84(Suppl II):II-68.

5. Sideris EB, Rao PS, Lloyd TR, et al: International experience with atrial septal defect occlusion by the buttoned device. Am Heart $J$ 1994; 128:1022-1035.
6. Hellenbrand WE, Fahey JT, McGowan FX, et al: Transesophageal echocardiographic guidance of transcatheter closure of atrial septal defect. Am J Cardiol 1990;66:207-213.

7. Sideris EB, Sideris SE, Fowlkes JP, et al: Transvenous atrial septal defect occlusion in piglets with a "buttoned" double-disk device. Circulation 1990;81:312-318.

8. Minich LL, Snider AR, Beekman RH: Use of echocardiography during placement of the buttoned double-disk device for atrial septal defect closure. Video J Echo 1992;2:65-73.

9. Rosenfeld HM, van der Velde ME, Sanders SP, et al: Echocardiographic predictors of good candidacy for transcatheter atrial septal defect closure. (Abstract) Circulation 1992;86(Suppl I):I-42. 
